\title{
Green Building Practices on Waste Minimization in China Construction Industry
}

\author{
Bernice Xin Yi Lee ${ }^{1 *}$, Mohanadoss Ponraj ${ }^{2}$, Hasti Widyasamratri ${ }^{3}$, Jie Wang ${ }^{4}$ \\ ${ }^{1}$ Department of Civil Construction Engineering, Faculty of Engineering Science, Curtin University, CDT 250, Miri, 98009 , \\ Sarawak, Malaysia \\ ${ }^{2}$ Department of Biological Sciences, School of Mathematics and Natural Sciences, The Copperbelt University, Riverside, \\ Jambo Drive, PO Box 21692, Zambia \\ ${ }^{3}$ Department of Urban and Regional Planning, Faculty of Engineering, Sultan Agung Islamic University, Semarang, Indonesia \\ ${ }^{4}$ School of Hydrology and Water Resources, Nanjing University of Information Science \& Technology, 219 Ningliu Rd., \\ Nanjing, Jiangsu Province 210044 , China \\ *Correspondence: bernicexinyilee@gmail.com
}

SUBMITTED: 15 October 2021; REVISED: 9 December 2021; ACCEPTED: 9 December 2021

ABSTRACT: In China, a common practice for construction waste management is to dispose of it in landfills. A 5\% construction waste recycling rate and ongoing insufficient landfilling practice resulted in decreased environmental and socioeconomic well-being. Management hierarchy that starts with rethink, redesign, reduce, reuse, refurbish, recycle, incineration, and finally disposal is a probable strategy to facilitate construction waste minimization in China. The green building concept pursued by China also served as a promising tool in evaluating the performance of Chinese green buildings. Barriers include lack of standard operating procedure in waste minimization, immature recycling technology and an undeveloped recycling market, leading to poor performance in construction waste minimization. Several strategies are proposed to ameliorate the current condition in China's construction sector. Even though results reveal that China falls behind in the engagement of green building compared to developed countries, green materials are utilized in various building structures such as flooring, roofs, walls, and outdoor pavements. Lastly, the benefits and shortcomings of two green material technologies, in particular material selection and recycling, applied in China were reviewed.

KEYWORDS: Construction waste minimization; green materials; environmental policy; green building rating systems

\section{Introduction}

Over the past decade, the increased generation of construction waste has attracted considerable attention due to its environmental impacts [1]. Construction waste, defined as solid waste generated from construction, renovation, and demolition activities, has a wide range of environmental consequences, including raw material depletion, pollution, ecosystem deterioration, and waste generation [2]. Hence, effective construction waste management is required to avoid these negative repercussions on the environment. In the World Economic Situation and Prospects 2021 report, the United Nations Department of Economic and Social 
Affairs (UN DESA) and the United Nations Conference on Trade and Development (UNCTAD) considered countries, namely Cambodia, China, Nigeria, Sri Lanka, Malaysia, Taiwan, Singapore, Hong Kong, and so on, as countries with developing economies. The building industry plays a substantial role in the contribution of China's national economy under rapid urbanization $[3,4]$. Seeing that, the adverse impacts caused by the large quantity of construction waste generated in China are inevitable. Thus, it is necessary to implement a review of China's status and government policies on construction waste minimization to provide an overview of current strategies and challenges faced in China. To address the considerable volume of construction waste generated in China, the green building concept, a promising initiative that aims to achieve sustainable development in social, environmental, and economic pillars, is being pursued [5]. Green building with increased energy, water, and material efficiencies can be achieved by implementing green technologies throughout the lifecycle of buildings. Construction waste minimization that utilizes comprehension of the root causes of waste generation is a vital component in construction waste management because measures will be conducted to reduce construction waste at the source [6]. In this article, the green building strategies used to minimize construction waste in China are discussed. This research also aimed to analyze the benefits and shortcomings of each green material technology.

\section{Green building (GB) and green building rating systems (GBRS)}

With the interest in sustainable development, the concept of green building (GB) emerged in the 1960s. GB is a concept aimed at providing solutions to reduce the environmental effects of construction projects, hence improving the wellbeing of the community and environment [7]. Materials that are more eco-friendly or technologies that are capable of reducing the use of materials, energy, and water are promoted through this architectural concept. Green building is also a holistic practice that strives for sustainability achievement through proper planning, design, construction, management, demolition, and waste remediation [8]. To define the GB standards, label certifications and facilitate the design of GB, several green building rating systems (GBRS) have been established by governments, professional associations as well as independent organizations [8,9]. GBRS like BREEAM, LEED, Green Mark, GBI, and Green Star are utilized as tools to judge buildings' performance by adhering to criteria such as energy efficiency, water efficiency, materials, and resources. On the other hand, construction waste management is a vital portion of various GBRS as the "materials" category constitutes $8-12 \%$ of GBRS credits [7,10].

\section{Construction waste management}

Construction and demolition waste are materials that are unwanted or damaged as a result of construction, renovation, refurbishment, or demolition [7]. Construction waste can be differentiated into seven categories, namely gypsum wallboard and plaster, brick and clay tile, concrete, asphalt concrete, asphalt shingles, steel and wood products. Apart from that, the classification of construction waste can also be controlled by the stable chemical properties, hence inert or non-inert waste are classified as shown in Figure 1 [8]. As illustrated in Figure 1 , inert construction waste refers to materials that remain stable in chemical reactions and are appropriate for reuse and recycling purposes, in particular land reclamation, road construction, 
and recycled aggregate [9]. Non-inert waste that cannot be reused or recycled is commonly disposed of in landfills [7]. However, landfilling is not a good option when it comes to construction waste management as it consumes land capacity rapidly [9]. Not to mention that landfilling also leads to environmental deterioration with the generation of methane, carbon dioxide, and leachate during the anaerobic decay of waste [11].

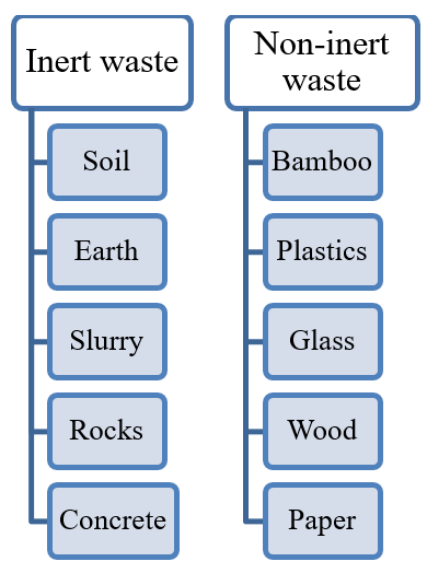

Figure 1. Classification of construction waste.

According to Lu et al. [11], construction waste makes up about $25 \%$ of the total solid waste disposed of in landfills. Various measures have been established to manage and mitigate the adverse impacts that they bring forth, where the most popular strategy is the "Reduce, Reuse, and Recycle" principle. Prevention of the construction waste being generated refers to reduction [9]. This practice utilizes the enactment of government legislation and low-waste technologies to alleviate and avoid waste generation throughout the construction process. Reuse means utilizing useful materials again for the same or new function. For instance, plastic waste can be utilized as material packaging whereas interior fixtures and furniture can be produced with timber waste $[9,12]$.

Furthermore, recycling involves the remanufacturing of construction waste as raw materials to produce new materials such as bricks and recycled aggregates [13]. As shown in Figure 2, recycling is the last resort before disposing of the construction waste by incineration or disposal. Hong Kong's construction waste management has been included in the "3R + I" principle compared to the traditional "3R" strategy as Hong Kong generates a large proportion of timber waste and has limited landfill space [14]. Moreover, Umar et al. also emphasized the addition of Rethink," Redesign and Refurbish to the waste hierarchy principle to promote optimum profits from products and reduce waste generation [1]. To realize the maximum ecofriendly outcome, particularly zero waste, the waste management hierarchy portrayed in Figure 2 should be followed as a guideline. 


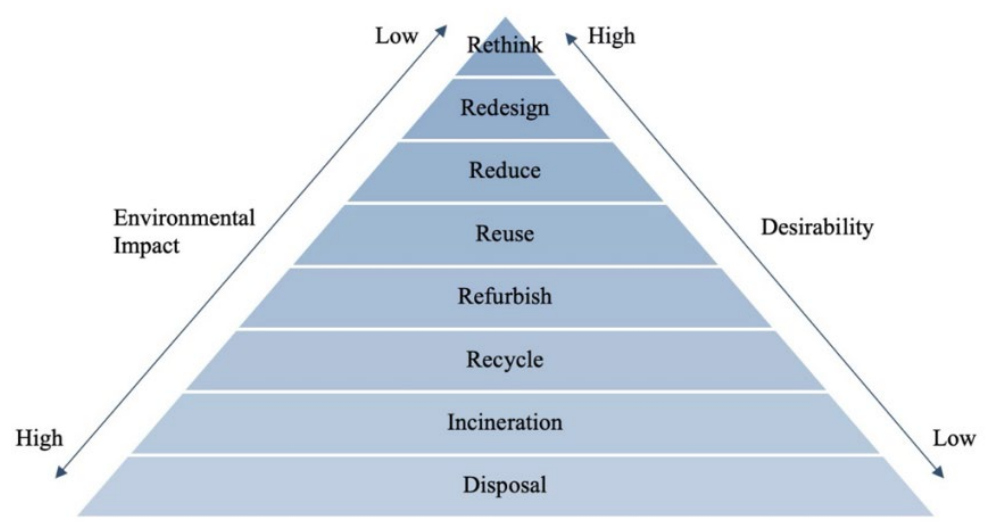

Figure 2. Waste management hierarchy.

Rethink and redesign strategies should be used in the design process to investigate more efficient and innovative methods of material utilization; refurbishing is the process of fixing or repairing damaged items or structures before replacing them [15]. A vital component of construction waste management is waste minimization, which aims to reduce the generated waste volume and thus limit the amount of hazardous and persistent waste products created [1]. Developing countries such as China have worse construction waste issues as compared with other Western developed countries [9]. Hence, the importance of construction waste minimization cannot be neglected. Table 1 summarizes the construction waste minimization strategies adopted in different developing countries.

Table 1. Various strategies are adopted for construction waste minimization.

\begin{tabular}{|c|c|c|}
\hline Country & Waste minimization strategies & References \\
\hline China & $\begin{array}{l}\text { a. Enactment of Provisions of Urban Construction Waste Management policy } \\
\text { b. Adoption of construction waste generation index for the estimation of waste amount } \\
\text { c. Recommendation on material selection } \\
\text { d. Utilizes GBRS (Green Building Evaluation Label) } \\
\text { e. Adoption of landfill charging schemes } \\
\text { f. Establishment of tax reduction and bonus in the use of secondary construction } \\
\text { materials }\end{array}$ & {$[4,9,16,17]$} \\
\hline Singapore & $\begin{array}{l}\text { a. Execution of General Waste Collection System } \\
\text { b. Impose expensive waste disposal fee } \\
\text { c. Implementation of efficient waste segregation } \\
\text { d. Utilizes GBRS (Green Mark) } \\
\text { e. Adoption of developed construction waste recycling technologies and facilities } \\
\text { f. Provision of recycling companies list to waste generators }\end{array}$ & {$[14,18,19,20]$} \\
\hline South Korea & $\begin{array}{l}\text { a. Enactment of Construction Waste Recycling Promotion Act } \\
\text { b. Obliged in the use of recycled aggregates } \\
\text { c. Provision of recycled aggregate products quality certification system } \\
\text { d. Establishment of waste information exchange system }\end{array}$ & {$[14,21]$} \\
\hline Hong Kong & $\begin{array}{l}\text { a. Establishment of Waste Disposal Ordinance } \\
\text { b. Enactment of Construction Waste Disposal Charging Scheme } \\
\text { c. Provision of the waste management plan (Source reduction, deconstruction and } \\
\text { waste segregation) } \\
\text { d. Establishment of pilot recycling plant } \\
\text { e. Utilizes GBRS (HK-BEAM) }\end{array}$ & {$[3,14,22]$} \\
\hline
\end{tabular}

\section{Existing status and government policy of environmental management practice in selected developing countries}

The status and adopted government policy in two developing countries, namely Singapore and China, are discussed in the construction waste minimization context. 


\subsection{Singapore}

Singapore generated 1,624,500 tons of construction waste in 2018 that took up around $21 \%$ of total solid waste, and 99\% of construction waste was recycled [23]. The reason behind Singapore's success in achieving a higher recycling rate of construction waste is the adherence to the construction waste minimization strategies listed in Table 1. A guideline on the usage of recyclables has been established by the Building and Construction Authority (BCA), while the National Environment Agency (NEA) provides information on construction waste generation and recycling. Furthermore, a site segregation plan is prepared for waste generators in Singapore to effectively sort different types of materials into designated categories. During the stimulation journey of green building in Singapore, the adoption of GBRS, namely Green Mark, plays an important role in boosting construction stakeholders' green behavior [19]. Moreover, a general waste collection system was introduced to facilitate the waste recycling process in Singapore [14]. However, the description of the recycling process of construction waste is limited, even though NEA did specify that crushed concrete will be used to produce recycled aggregates for structural and non-structural applications. On the other hand, Singapore also imposes high illegal waste dumping and disposal fees to promote recycling [23]. In addition, concrete recovery with the acquisition of demolition equipment is encouraged through the Construction Productivity Capability Development Fund. To promote the usage of recycled materials in the construction sector, an accreditation scheme to evaluate the recycled aggregate's quality, a list of recycling plants, and recycled aggregate suppliers are provided as the resources in constructing a green building [19].

\subsection{China}

Due to rapid urbanization in China, a substantial amount (2.36 billion tons) of construction waste is generated annually, and it comprises $30-40 \%$ of total solid waste [24,25]. Worse, only $5 \%$ of the average recycling rate of construction waste is recorded in comparison to $70-95 \%$ recycling rates in several developed countries [25]. LV et al. (2021) commented that the recycling rate of municipal solid waste (MSW) in China remained low over a 12-year period, where $97.8 \%$ of MSW disposal in 2006 decreased to $96.0 \%$ in 2018 . National policies, in particular provisions of the Urban Construction Waste Management policy, have been enacted in China to improve China's performance in construction waste management [4]. To boost waste generators' proactiveness in construction waste management, a Technical Code for Recycling Construction and Demolition Waste that emphasizes on-site sorting and recycling has been issued [26]. To fulfil green building standards, financial incentives for recycling, penalties for illegal waste dumping, as well as higher incineration and landfilling costs are established [4]. To encourage technical development in China, a national research and development plan aimed at developing concrete recycling and solid waste equipment technologies was established [4]. Management documents issued in those cities overlooked the feasible construction waste recycling strategies, and thus the smaller cities fell behind in green building achievement. Even though China utilizes the GBRS Green Building Evaluation Label as a measure to remediate building-associated environmental issues, Bao et al. (2020) concluded that the green building concept does not play an important role in the improvement of construction waste management [9]. Besides, the transfer of large construction waste quantities from urban to rural areas leads to the "construction waste surrounding" issue. By 
failing to notice the illegal dumping activities, the rural community suffered from adverse health impacts caused by open dumping grounds [25].

\section{Present standing of green materials for construction}

Starting from this section, only the green building strategies adopted in China are discussed. The application of green materials in China is majorly focused on building segments, particularly flooring, roofs, walls, and outdoor pavements [27,28]. Green building is evaluated with various criteria. For example, criteria include sustainable site, water efficiency, energy and atmosphere, materials and resources, indoor environmental quality, innovation in design and regional priority. Credits are obtained through the Leadership in Energy and Environmental Design (LEED) certification administered by the United States [6]. The construction waste minimization-related credits illustrated in Figure 3 totaled 11 out of 110 points in the LEED framework. Thus, the construction waste minimization-related credits can be used to access the accomplishment of green building projects in construction waste minimization.

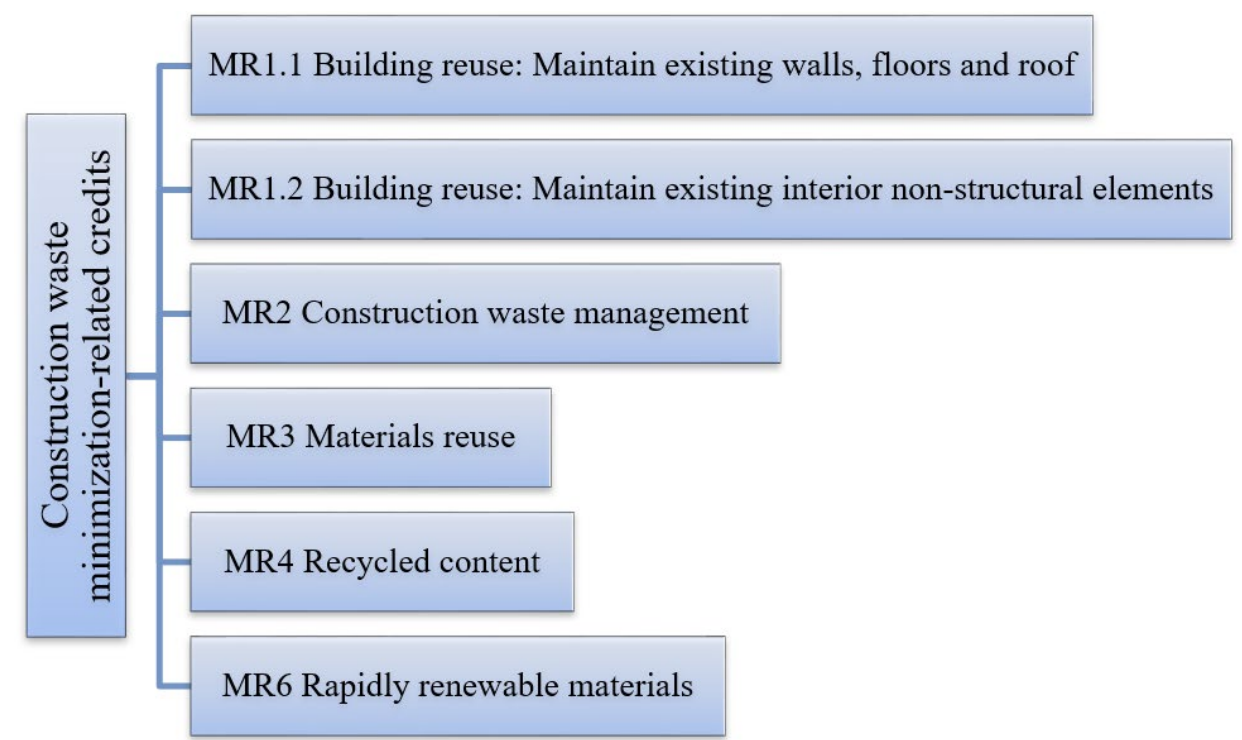

Figure 3. Construction waste minimization-associated credits in LEED.

Several statistical tests were conducted by Chi et al. to compare the performance of LEED-certified projects in construction waste minimization and concluded that China falls behind the United States (US) in construction waste minimization performance [6]. In terms of MR1, particularly building reuse, most of the old buildings in China were dismantled to create space for new buildings without considering their reuse value [29]. In short, Chinese contractors prefer brand-new building materials over salvaged materials. China's building projects attained similar low scores in both MR3 and MR4 due to misconceptions about the poor quality and durability of reused and recycled materials. Another key point that caused USGB projects to surpass China-GB projects is that Chinese society interprets construction waste minimization-related credits as subsidiary credits in GB projects. Without public awareness of the importance of construction waste minimization in China, the interest level of stakeholders participating in waste management is low, which then leads to an undeveloped construction waste recycling market [6]. In another study conducted by Bao et al., the MR2 construction waste management criterion scored low in China GB projects due to the lack of waste disposal procedures in regional regulations. This study also agreed that project stakeholders in China 
doubt the reusable and recycled materials' quality and durability, thus are unwilling to take responsibility for the risks accompanied by reusable and recycled materials. Additionally, the traditional Chinese mindset leads to reduced profitability of recycled products in China due to low demand for reusable or recycled materials. Even though the Chinese government does provide cost savings when reusable or recycled materials are applied in GB projects, the adoption cost of reusable or recycled materials still burdens the overall project costs [9]. To reduce the utilization of natural virgin materials in building projects, MR4 recycled content has been introduced. However, the project developer can only gain this credit with the evidence of recycled components' proportion. Not to mention that the recycled content value is often not labelled in the current Chinese market, there is also an absence of a standard operating procedure for project developers to collect data in China. As a result, cases of data fabrication are common in China [9, 29]. Implementation of green building features in developing countries/cities is lagging that in developed cities, as portrayed in Table 2. This shows that the obstacles preventing green building applications are greater in developing countries, namely Singapore, Shanghai, and Hong Kong.

Table 2. Green building penetration rates in different regions.

\begin{tabular}{llcc}
\hline Status of development & Country/Cities & Green building penetration percentage (\%) & References \\
\hline \multirow{2}{*}{ Developed } & London & 68 & {$[30]$} \\
& Paris & 64 & {$[30]$} \\
\hline \multirow{3}{*}{ Developing } & Singapore & 30 & {$[31]$} \\
& Shanghai & 15 & {$[31]$} \\
& Hong Kong & 4 & {$[31]$} \\
\hline
\end{tabular}

\section{Suggestion and strategy to improve current environmental management practice}

The existing methodologies in terms of construction waste management implemented in China are outlined in Table 1 and Section 4.2. Whereby the green building performance of China's construction projects is discussed in Section 5. As outlined in the previous section, the GB performance in China is unfavorable in construction waste minimization. Therefore, the following suggestions are formulated in the economic, political, social, and technological aspects to address these issues.

\subsection{Economic aspect}

The incorporation of on-site waste segregation activities requires extra labour costs to achieve effective MR2 construction waste management. In addition, recycled materials are more expensive in China's recycled building products market. To prevent this condition from occurring, the cultivation of a mature construction waste recycling market should be established. Besides, a specific fund can be provided to subsidy the adoption of recycled construction materials. For instance, greater use of recycled materials in construction can receive higher financial incentives [9].

\subsection{Political aspect}

Bao et al. commented that the construction waste management regulations are incomplete in China, with only minimal cities such as Shanghai, Shenzhen, and Beijing having their own regional construction waste management regulations. Even worse, the regulations stipulated 
are incomparable to those enacted in developed countries, as only a few insights into the improvement of construction waste are provided. Hence, the formulation of regulations should be conducted in-depth and in a straightforward manner for easy enforcement. Furthermore, systematic construction waste minimization-related regulations should be stipulated both nationally and regionally to prevent confusion [9, 28, 29]. Moreover, strict enforcement of regulations as well as penalties should be implemented, learning from Singapore's experience. An environmental administration body should be appointed to supervise and monitor the construction waste management process. In addition, an effective circular economy model should be established for construction waste management as recycled construction waste can also be utilized in other industries, including metallurgical, glass, ceramic, paper, and timber industries. Reuse of buildings and civil infrastructure should also be advocated to reinforce the source of control [25].

\subsection{Social aspect}

Due to a lack of education, the construction stakeholders' awareness of construction waste management is low, and this results in a high devotion towards criteria such as quality, cost, safety, and duration, instead of concerning the environmental impacts. To encounter this problem, various social media platforms, namely television programs and newspapers, can be used to raise awareness of construction waste management and the benefits of green building. Besides, construction waste management practitioners that comprise engineers, contractors, architects, and workers should be provided with training courses to ensure effective construction waste management performance in any construction project $[9,32]$.

\subsection{Technological aspect}

Interviewees in Bao et al.'s study claimed that most equipment utilized in China is imported from western countries to manufacture recycled construction waste, which significantly resulted in expensive recycled materials [9]. Additionally, adequate techniques for construction waste minimization and treatment guidelines are insufficient in China. Hence, the Chinese government should allocate more funds to assist with construction waste management-related research and cooperative development of green technologies with other countries so a solid technical foundation can be attained as soon as possible. Furthermore, a proper standard operating procedure for recycled content data collection and compliance with recycled construction materials standards should be provided $[9,32]$.

\section{Green materials technologies}

The green materials technologies discussed in this section are solely intended for the minimization of construction waste.

\subsection{Material selection (Rethink and redesign)}

Every $1 \mathrm{~m}^{2}$ of building in China is estimated to require $50-60 \mathrm{~kg}$ of steel, $0.15-0.17$ tons of brick, and 0.2-0.23 tons of concrete. Consequently, a substantial amount of waste will be produced without any source reduction. Therefore, the choice of materials is important when it comes to the construction of buildings. Buildings constructed in China before the year 2020 
only serve the purpose of maintaining the structure. However, after the green building concept is promoted in the country, China applied modern walls with reduced wall thickness as shown in Table 3. This does not only save the materials required for construction but also achieves the "Reduce" strategy proposed in the waste management hierarchy. With the adoption of energy-saving materials, the materials needed for constructing a wall have decreased significantly. Not to mention that the modern wall has better benefits, namely increased thermal resistance and better wall heat storage capacity [28,29,32]. In the past, common construction materials used in China included wood, stone, steel, and concrete. With the promotion of green building materials, bamboo is suggested to replace wood as a better construction material [28]. As a typical green material, bamboo not only reduces carbon emissions via carbon dioxide sequestration during growth but also has the potential to store carbon dioxide. not only interested in bamboo's benefits being environmentally friendly, but bamboo also exhibits advantages such as being fast-growing and easily accessible, lightweight and durable, as well as inexpensive [27].

Table 3. The traditional and modern wall built in China.

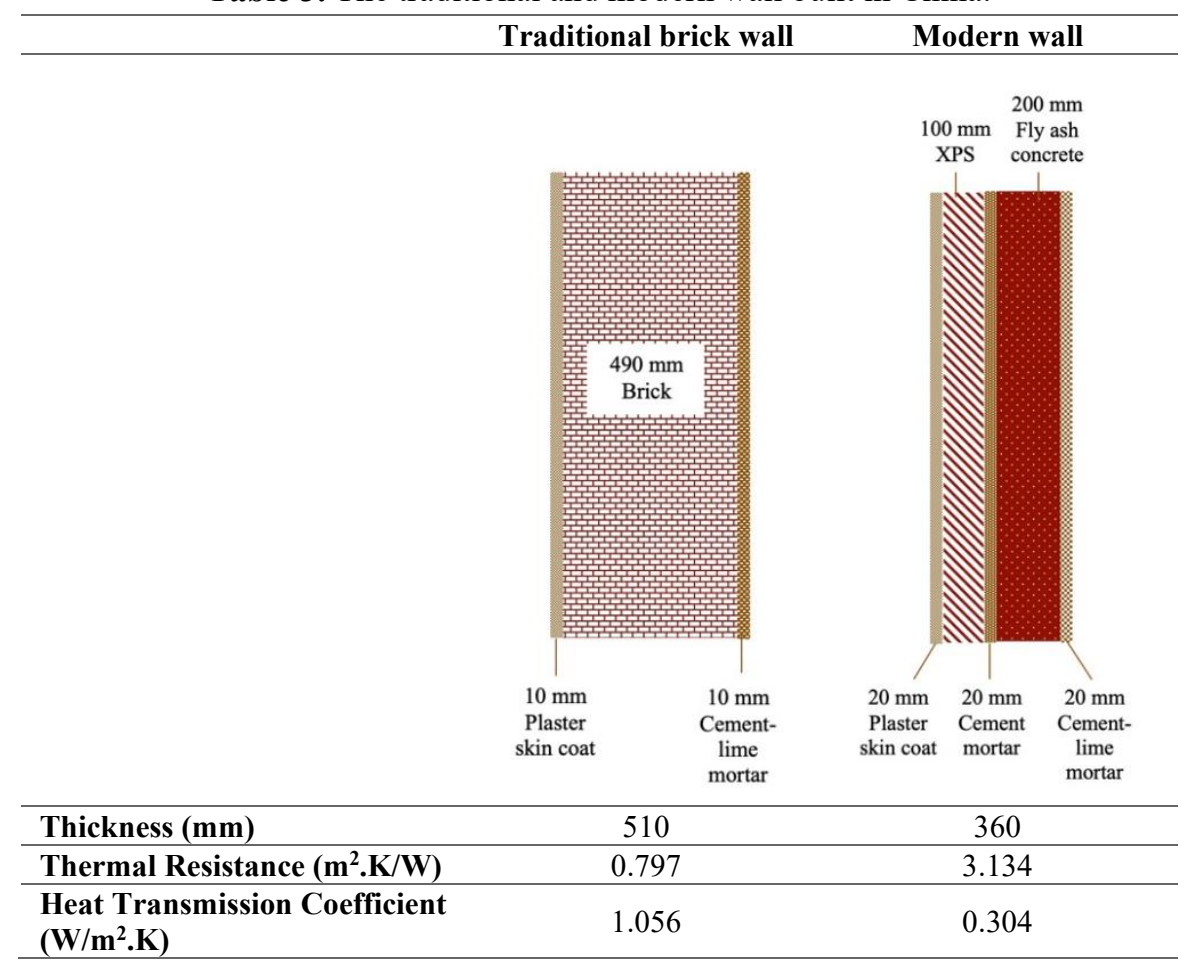

Nowadays, bamboo is preferred over wood as a renewable construction material with a short harvest time of 3-5 years and abundant resources distributed in the Asia-Pacific, Americas, and Africa regions [27,33]. Nurdiah described that bamboo is a very strong fiber that is compatible with concrete, steel, and wood. Bamboo is deemed one of the strongest building materials because it has two times greater compressive strength than concrete, comparable tensile strength to steel and higher shear stress than wood. Aside from that, bamboo has also proven its resilient properties under natural disaster conditions like earthquakes and high-velocity winds. The advantage of bamboo's being low cost is affirmed and it is often called "the wood of the poor." For instance, the low cost of bamboo houses in India is demonstrated [34]. Therefore, the application of bamboo as a green building material is increasing in numbers internationally, where the bamboo applications in the construction sector are listed in the following: 
a) Green School, OBI Great Hall, Dodoha Mosintuwu and Bamboe Koening restaurant in Indonesia [33].

b) Aseismic buildings in China [27].

c) Clinton Presidential Library ceiling in the United States [35].

Various policies have been introduced to encourage the application of bamboo for building materials, such as the "National Bamboo Mission" launched by the government of India and the "Replacing Wood with Bamboo" program established by the Chinese government. Nevertheless, bamboo as an alternative building material has its disadvantages, namely poor durability, a requirement for preservation, complicated quality control, and insufficient processing techniques [27]. One of the major criteria in materials selection, especially in structural works is the durability of construction materials. Bamboo is considered a material with poor durability as it has high susceptibility to corrosion, moth and mildew without any pretreatment. Furthermore, the application of bamboo in buildings is hindered by the lack of proper standards and specifications in China as bamboo's feasibility and effectiveness as a building material have yet to be demonstrated in the Chinese construction sector [27]. As bamboo is highly vulnerable to termites and fungal attacks, preservation methods such as immersion, injection and gravitational soak diffusion of borax boric acid into the bamboo are essential to prolong its lifespan [33]. Besides, bamboo application in the Chinese construction sector is obstructed with limited research and development because the knowledge on producing bamboo flooring, ceiling, partition wall or other complex structure is not up to date $[27,33]$.

\subsection{Recycling}

Zhao et al. asserted the indispensable construction materials are mainly comprised of cement and concrete in traditional buildings. However, cement has cons like substantial mineral waste and pollution generation during production. Hence, ecological cement that utilizes recyclable wastes as raw materials in production is a major green material technology to cut down on construction waste. In comparison to the usage of cement, ecological cement also outnumbered conventional cement in terms of resource consumption and carbon emissions. The wastes, particularly volcanic ash and steel slag, have the potential to be used in the production of ecological cement [28]. With advanced technology in doping mixed materials in the cement, it is possible to replace $80 \%$ of the original content of cement and thus produce green ecological concrete [36]. Apart from that, wastes such as fly ash, slag ash, and concrete hollow fast can be used as raw materials for the manufacture of green wall materials [28]. The use of fly ash walls in modern walls, portrayed in Table 3 , also illustrates the benefit of utilizing green wall materials to improve the overall performance of the wall. Ren et al. highlight that China falls behind the western developed countries in the development of green wall materials. But China developed the small solid Bo brick that has benefits over the traditional wall with the incorporation of industrial waste into the wall material. Namely, the aspects of Bo brick, such as replacing raw resources of wall materials with industrial waste and utilizing the pressure steam method in manufacturing wall materials, bring forth benefits like reduced use of cement, calcium carbide or lime, a minimized production cycle, and better product performance compared to non-autoclaved cement products [36]. The surplus waste, particularly stone, earth, industrial or reservoir sludge, and non-hazardous inorganic waste, produced from building 
construction can be recycled with a utilization ratio ranging from $15-90 \%$ to produce green construction materials such as concrete aggregates, bricks, and ceramic tile. Moreover, a 90\% recycled ratio of wooden materials can create medium-density fiberboard and wooden furniture [37]. Recycling construction waste has the potential to reduce waste at the source while also producing useful green materials that are environmentally friendly and renewable; however, the disadvantages of implementing this strategy must not be overlooked. Disadvantages associated with the application of recycled materials in the construction sector include the requirement for mature recycling technologies, a developed market for recycled construction products, and an effective management system [25]. Compared to countries well known for construction waste recycling such as Japan and Singapore, recycling technologies utilized in China, namely green concrete for road application, are sparse as the full potential of valuable wastes, including metals, glass, wood, and plastic, is not realized when they are recycled as normal waste [32,37,38]. Advanced recycling technologies such as concrete and cement segregation, carbonization of construction waste, and the manufacture of recycled concrete with different strength properties must be realized in China to fully attain the construction waste's recycling potential $[25,39,40]$. Lessons learnt from South Korea in establishing an effective waste management system include a waste information exchange system, so waste type, quality, amount, and price can be known conveniently [41]. Similarly, the adoption of a recycling strategy in construction waste reduction should refer to Singapore's practices by establishing complete guidelines on overall waste management and providing a price advantage to recycled materials.

\section{Conclusion}

The undertaking of construction activities does bring forth positive economic growth in China, but the negative environmental and socio-economic repercussions cannot be avoided, leading to the formulation of construction waste management. Construction waste minimization takes up a major portion of the overall construction waste management, and the construction waste minimization-related credits in green building rating systems (GBRS) can be used as a tool to access the green building performance in China's building projects. After the evaluation of green building status, the performance of Chinese buildings attained an unsatisfactory score in construction waste minimization due to barriers from the economic, political, social, and technological dimensions. The analysis of green building performance brings convenience to practitioners and researchers in the application of construction waste minimization, as construction waste minimization-related credits can be employed to improve construction waste management practices in China. Lastly, two green materials technologies adopted in China, namely material selection and recycling, are discussed. By choosing better choices of materials, the use of virgin construction materials can be saved with the example of the modern green wall. Besides, bamboo is also a promising green and renewable construction material in China after adequate pre-treatment and quality control. Recyclable wastes from various industries can be remodeled as ecological cement, green walls, green concrete, as well as furniture. However, the technological, political, and social challenges are the major shortcomings of the use of recycled waste in construction waste minimization. With an increasing interest in sustainability issues, there is a trend for developing countries to develop and utilize new green materials suitable for their countries. Nevertheless, this study showed 
China has to embrace and realize the green building concept to ensure China is developing sustainably.

\section{Acknowledgements}

The authors thank Curtin University Malaysia for facilitating this work. Collaboration from Copperbelt University Zambia, Sultan Agung Islamic University Indonesia, and Nanjing University of Information Science \& Technology China are highly appreciated.

\section{Competing Interest}

The authors declare that they have no known competing financial interests or personal relationships that could have appeared to influence the work reported in this paper.

\section{References}

[1] Umar, U.A.; Shafiq, N.; Malakahmad, A.; Nuruddin, M.F.; Khamidi, M.F. (2017). A review on adoption of novel techniques in construction waste management and policy. Journal of Material Cycles and Waste Management, 19, 1361-1373. https://doi.org/https://doi.org/10.1007/s10163016-0534-8.

[2] Wu, Z.; Jiang, M.; Cai, Y.; Wang, H.; Li, S. (2019). What Hinders the Development of Green Building? An Investigation of China. International Journal of Environmental Research and Public Health, 16, 3140. https://doi.org/https://doi.org/10.3390/ijerph16173140.

[3] Chen, X.; Lu, W.; Xue, F.; Xu, J. (2018). A cost-benefit analysis of green buildings with respect to construction waste minimization using big data in Hong Kong. Journal of Green Building, 13, 61-76. https://doi.org/https://doi.org/10.3992/1943-4618.13.4.61.

[4] Lv, H.; Li, Y.; Yan, H.B.; Wu, D.; Shi, G.; Xu, Q. (2021). Examining construction waste management policies in mainland China for potential performance improvements. Clean Technologies and Environmental Policy, 23, 445-462. https://doi.org/https://doi.org/10.1007/ s10098-020-01984-y.

[5] Robichaud, L.B., Anantatmula, V.S. (2011). Greening project management practices for sustainable construction. Journal of management in engineering, 27, 48-57. https://doi.org/https://doi.org/10.1061/(ASCE)ME.1943-5479.0000030.

[6] Chi, B.; Lu, W.; Ye, M.; Bao, Z.; Zhang, X. (2020). Construction waste minimization in green building: A comparative analysis of LEED-NC 2009 certified projects in the US and China. $\begin{array}{lllll}\text { Journal of } & \text { Cleaner } & \text { Production, } & 256, & \end{array}$ https://doi.org/https://doi.org/10.1016/j.jclepro.2020.120749.

[7] Lu, W.; Chi, B.; Bao, Z.; Zetkulic, A. (2019). Evaluating the effects of green building on construction waste management: A comparative study of three green building rating systems. Building and Environment, 155, 247-256. https://doi.org/https://doi.org/10.1016/j.buildenv. 2019.03.050.

[8] Wu, Z.; Yu, A.T.W.; Poon, C.S. (2019). An off-site snapshot methodology for estimating building construction waste composition - a case study of Hong Kong. Environmental Impact Assessment Review, 77, 128-135. https://doi.org/https://doi.org/10.1016/j.eiar.2019.03.006.

[9] Bao, Z.; Lu, W.; Chi, B.; Hao, J. (2020). Construction waste management performance in green building: contextualising LEED in China. Detritus, 125. https://doi.org/https://doi.org/10.31025/2611-4135/2020.13992.

[10] Lu, W.; Webster, C.; Peng, Y.; Chen, X.; Zhang, X. (2017). Estimating and calibrating the amount of building-related construction and demolition waste in urban China. International Journal of Construction Management, 17, 13-24. https://doi.org/https://doi.org/10.1080/15623599. 2016.1166548.

[11] Lu, W.; Chen, X.; Peng, Y.; Shen, L. (2015). Benchmarking construction waste management performance using big data. Resources, Conservation and Recycling, 105, 49-58. https://doi.org/https://doi.org/10.1016/j.resconrec.2015.10.013. 
[12] Wang, J.; Yu, B.; Tam, V.W.Y.; Li, J.; Xu, X. (2019). Critical factors affecting willingness of design units towards construction waste minimization: An empirical study in Shenzhen, China. Journal of Cleaner Production, 221, 526-535. https://doi.org/https://doi.org/10.1016/ j.jclepro.2019.02.253.

[13] Mak, T.M.W.; Iris, K.M.; Wang, L.; Hsu, S.C.; Tsang, D.C.W.; Li, C.N.; Yeung, T.L.Y.; Zhang, R.; Poon, C. S. (2019). Extended theory of planned behaviour for promoting construction waste recycling in Hong Kong. Waste management, 83, 161-170. https://doi.org/10.1016/j.wasman.2018.11.016.

[14] Wu, Z.; Yu, A.T.W.; Poon, C.S. (2020). Promoting effective construction and demolition waste management towards sustainable development: A case study of Hong Kong. Sustainable Development, 28, 1713-1724. https://doi.org/10.1002/sd.2119.

[15] Laovisutthichai, V.; Lu, W.; Bao, Z. (2020). Design for construction waste minimization: guidelines and practice. Architectural Engineering and Design Management, 1-20. https://doi.org/10.1080/17452007.2020.1862043.

[16] Huang, T.; Shi, F.; Tanikawa, H.; Fei, J.; Han, J. (2013). Materials demand and environmental impact of buildings construction and demolition in China based on dynamic material flow analysis. Resources, Conservation and Recycling, 72, 91-101. https://doi.org/https://doi.org/10.1016/j.resconrec.2012.12.013.

[17] Li, J.; Ding, Z.; Mi, X.; Wang, J. (2013). A model for estimating construction waste generation index for building project in China. Resources, Conservation and Recycling, 74, 20-26. https://doi.org/10.1016/j.resconrec.2013.02.015.

[18] Sustainable construction - A Guide on the use of recycled materials. (Accessed on September 10, 2021) Available online: https://www1.bca.gov.sg/docs/default-source/docs-corpbuildsg/sustainability/sc recycle final.pdf.

[19] Construction productivity capability development fund. (Accessed on September 10, 2021) Available online: https://www.bca.gov.sg/Professionals/GovAsst/govasst.html.

[20] Waste management Infrastructure. (Accessed on September 10, 2021) Available online: https://www.nea.gov.sg/our-services/waste-management/3r-programmes-and-resources/wastemanagement-infrastructure/solid-waste-management-infrastructure.

[21] Waste recycling. (Accessed on September 10, 2021) Available online: http://eng.me.go.kr/eng/web/main.do.

[22] Lu, W.; Tam, V.W.Y. (2013). Construction waste management policies and their effectiveness in Hong Kong: A longitudinal review. Renewable and Sustainable Energy Reviews, 23, 214-223. https://doi.org/10.1016/j.rser.2013.03.007.

[23] Annual report 2018. Environmental Protection Division, Singapore. (Accessed on September 10, 2021) Available online: https://www.nea.gov.sg/docs/defaultsource/resource/publications/environ-mental-protection-division-annual-report/epd-report-2018v4-(compressed).pdf

[24] He, L.; Yuan, H. (2020). Investigation of construction waste recycling decisions by considering consumers' quality perceptions. Journal of Cleaner Production, 259, 120928. https://doi.org/https://doi.org/10.1016/j.jclepro.2020.120928.

[25] Huang, B.; Wang, X.; Kua, H.; Geng, Y.; Bleischwitz, R.; Ren, J. (2018). Construction and demolition waste management in China through the 3R principle. Resources, Conservation and Recycling, 129, 36-44. https://doi.org/https://doi.org/10.1016/j.resconrec.2017.09.029.

[26] Technical code for recycling of construction \& demolition waste. (Accessed on September 10, 2021) Available online: https://www.mohurd.gov.cn/wjfb/201207/t2012\%200724 210771.html.

[27] Shen, L.; Yang, J.; Zhang, R.; Shao, C.; Song, X. (2019). The Benefits and Barriers for Promoting Bamboo as a Green Building Material in China-An Integrative Analysis. Sustainability, 11, 2493. https://doi.org/10.3390/su11092493.

[28] Zhao, H.; Wang, Y.; Qiu, W.; Qu, W.; Zhang, X. (2018). Research on the Application of Green Building Materials in China. IOP Conference Series: Earth and Environmental Science, 186, 012043. https://doi.org/10.1088/1755-1315/186/2/012043.

[29] Qui, Y.; Tannock, J.D.T. (2010). Dissemination and adoption of quality management in China: Case studies of Shanghai manufacturing industries. International Journal of Quality \& Reliability Management, 27, 1067 - 1081. https://doi.org/10.1108/02656711011084846. 
[30] Wadu Mesthrige, J.; Kwong, H.Y. (2018). Criteria and barriers for the application of green building features in Hong Kong. Smart and Sustainable Built Environment, 7, 251-276. https://doi.org/10.1108/SASBE-02-2018-0004.

[31] Hill, A.M. (2016). Comparison of Occupant Behavior in a Traditional, Green Featured, and LEED Certified Building Case. Master Thesis, Bowie State University, United States.

[32] Zhang, D.; Wu, W.; Fang, P. (2020). Research on the Development of Green Buildings in China. IOP Conference Series: Earth and Environmental Science, 555, 012095. https://doi.org/10.1088/1755-1315/555/1/012095.

[33] Nurdiah, E.A. (2016). The Potential of Bamboo as Building Material in Organic Shaped Buildings. Procedia - Social and Behavioral Sciences, 216, 30-38. https://doi.org/10.1016/j.sbspro.2015.12.004.

[34] Puri, V.; Chakrabortty, P.; Anand, S.; Majumdar, S. (2017). Bamboo reinforced prefabricated wall panels for low cost housing. Journal of Building Engineering, 9, 52-59. https://doi.org/10.1016/j.jobe.2016.11.010.

[35] Clinton Presidential Library. (Accessed on September 10, 2021) Available online: https://architizer.com/projects/clinton-presidential-library/.

[36] Ren, H.Y.; Wang, S.; Wang, C. (2015). General Analysis on Green Building Materials and Development in China. Applied Mechanics and Materials, 744-746, 1427-1430. https://doi.org/10.4028/www.scientific.net/AMM.744-746.1427.

[37] Wang, H.; Chiang, P.C.; Cai, Y.; Li, C.; Wang, X.; Chen, T.L.; Wei, S.; Huang, Q. (2018). Application of Wall and Insulation Materials on Green Building: A Review. Sustainability, 10, 3331. https://doi.org/10.3390/su10093331.

[38] Tam, C.M.; Tam, V.W.Y.; Tsui, W. S. (2004). Green construction assessment for environmental management in the construction industry of Hong Kong. International Journal of Project Management, 22, 563-571. https://doi.org/10.1016/j.ijproman.2004.03.001.

[39] Zhang, Y.; Kang, J.; Jin, H. (2018). A Review of Green Building Development in China from the Perspective of Energy Saving. Energies, 11, 334. https://doi.org/10.3390/en11020334.

[40] Zheng, L.; Wu, H.; Zhang, H.; Duan, H.; Wang, J.; Jiang, W.; Dong, B.; Liu, G.; Zuo, J.; Song, Q. (2017). Characterizing the generation and flows of construction and demolition waste in China. Construction and Building Materials, 136, 405-413. https://doi.org/10.1016/j.conbuildmat.2017.01.055.

[41] Wu, Z.; Ann, T.W.; Shen, L. (2017). Investigating the determinants of contractor's construction and demolition waste management behavior in Mainland China. Waste management, 60, 290-300. https://doi.org/10.1016/j.wasman.2016.09.001.

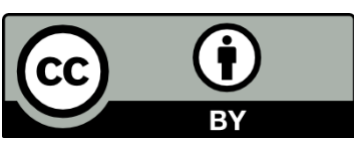

(C) 2021 by the authors. This article is an open access article distributed under the terms and conditions of the Creative Commons Attribution (CC BY) license (http://creativecommons.org/licenses/by/4.0/). 